\title{
Role of Oral Tranexamic Acid in Treating Patients of Melasma in A Charity Hospital of Lahore
}

\author{
MARIAM SHEIKH ${ }^{1}$, IKRAM UR RAHIM ${ }^{2}$, MUHAMMAD LATIF ${ }^{3}$, RABAIL MAJEED $^{4}$, MUHAMMAD AWAIS $^{5}$, SUNILA RIAZ $^{6}$ \\ ${ }^{1}$ Associate Professor of Dermatology, Akhtar Saeed Medical and Dental College Lahore \\ ${ }^{2}$ Professor of Medicine, Akhtar Saeed Medical and Dental College Lahore \\ ${ }^{3}$ Associate Professor of Medicine, Akhtar Saeed Medical and Dental College Lahore \\ ${ }^{4}$ Medical Officer of Dermatology, Akhtar Saeed Trust Hospital Lahore \\ ${ }^{5}$ Assistant Professor of Paedriatics, Akhtar Saeed Medical and Dental College \\ ${ }^{6}$ Department of Gynecology and Obstetric, Sheikh Zayed Hospital, Rahim Yar Khan \\ Correspondence to: Dr. Mariam Sheikh, Email: mariamsheikh1977@gmail.com, Cell: 0321-4022333
}

\begin{abstract}
Objective: To evaluate the efficacy and safety of oral tranexamic acid (TA) in the treatment of melasma

Method: This was a descriptive, cross sectional study which was performed in department of dermatology in Akhtar Saeed Trust Hospital, Lahore from April till December 2019. 70 patients of moderate to severe melasma were enrolled regardless of gender, > 18 years of age. $250 \mathrm{mg}$ oral TA was given BD for 3 months along with broad spectrum topical sunscreen. Follow up done on monthly basis, 2 months after stopping the treatment. Photographs were taken at first visit \& MASI (melasma area severity index) scoring done at start \& after 3 months of treatment. Side effects were noted down if present. Results were recorded \& analysed using SPSS.

Results: A total of 70 patients were enrolled, 44 females and 26 males. Mean age of patients was 30.7 . There was a significant decrease mean 3.4 in MASI scoring at 12 wks of treatment. 25 patients had good, 22 had fair, 7 had fair response to TA. No serious side effects were noted at end of treatment. No reversal of melasma was recorded at 2 months after stopping treatment.
\end{abstract}

Conclusion: Oral tranexamic acid is a quick \& effective treatment of patients of melasma.

Key words: Melasma, tranexamic acid, treatment.

\section{INTRODUCTION}

Tranexamic acid is a plasmin inhibitor, a derivative of amino acid lysine, that is used to stop excessive bleeding. It is (trans-4-(Aminomethyl) cyclohexane-carboxylic acid. It acts by competitively inhibiting the activation with its plasminogen activator through reversible interactions with its lysine binding sites. ${ }^{1,2,3}$ It blocks interaction between melanocytes and keratinocytes. So by using either oral or topical tranexamic acid can decrease and reverse any melasma-related dermal changes, like reduction of redness and number of vessels. ${ }^{4}$

Melasma is a common disorder which is more common in females as compared to males, which is only $10 \%$ of total cases. Melasma is a pigmentary disorder in which macules and patches of light to dark brown colour involve the photoexposed areas of face and neck. There are many causes of melasma, some are known but some are still not known yet. The known causes are sunexposure, genetic predisposition, pregnancy, use of oral contraceptive pills, thyroid disorder and certain drugs. $2,5,6$ Some factors influence the function of melanocytes, so they can contribute to the UV-induced pigmentation, such as factors include photo-induced hormones, growth factors, chemical and inflammatory mediators. ${ }^{2,6}$

Different treatment modalities like use of sunscreen, hypopigmenting agents, and laser therapy are used. Usually, bleaching agents are prescribed in combination with other therapies, such as tretinoin, topical corticosteroids, or superficial peeling agents. ${ }^{6,7,8,9}$ In recent times, some researchers found that tranexamic acid (TA), has hypo pigmentary effect on melasma lesions and prevents UV-induced pigmentation. 5,6,10,11,12,13
Although TA has emerged as a potential treatment for melasma, it has not been approved by food and drug administration of the United States for melasma and treatment remains controversial. ${ }^{14,15,16,17}$. Consequently, in this study, we conducted a systematic review to evaluate the therapeutic effect of TA for treating melasma. ${ }^{14}$

\section{MATERIALS AND METHODS}

This was a descriptive, cross-sectional study which was performed on 70 patients of melasma in Akhtar Saeed Trust Hospital, Lahore from April till December 2019. After taking permission from ethical committee of the institute, an informed written consent was taken from all enrolled patients. The inclusion criteria included both male and female patients with moderate to severe melasma with ages ranging above 18 years. Patients with age $<18$ years, pregnant \& lactating females, patients with chronic medical disorder (bleeding diathesis, heart disease, hypertension), presence of menstrual irregularities, patients taking anticoagulants and on oral contraceptive pills were excluded from the study.

All the patients who were enrolled, their detailed history was taken, the typing of melasma was noted with help of wood's lamp (epidermal, mixed, dermal) on examination. Required tests like platelet count, bleeding and clotting time were conducted. Those patients who had abnormalities in their tests were excluded.

Patients were prescribed oral tranexamic acid $250 \mathrm{mg}$ twice a day for 3 months. Only topical broad-spectrum sunscreen was prescribed along with it. For patient satisfaction evaluation results were rated as excellent if $>$ $90 \%$ improvement, good if $>70 \%$, fair $>40 \% \& 0-20 \%$ poor or no improvement. 
Any side-effects were noted down on each follow up visits, gastrointestinal symptoms like abdominal cramps, oligomenorrhea. All the findings were recorded \& analysed using SPSS.

\section{RESULTS}

A total of 70 patients were included in the study out of which females were 44 (62.9\%) and males were 26 $(37.1 \%)$. In table 1 , it shows the baseline characteristics of these patients like gender of patient, type, and pattern of melasma. Mean age of patients was 30.7 years. The duration of melasma ranges from 3 months to 12 years. Regarding type of melasma epidermal (71.4\%) was the commonest, followed by dermal in $11(15.7 \%)$ and mixed in $9(12.9 \%)$ of patients. Mixed pattern of melasma was present in (45.7\%) 32 patients, malar type was in $28(40 \%)$, centrofacial $8(11.4 \%)$ and mandibular in $2(2.9 \%)$ of patients.

MASI scoring 1 was done on 1 st visit and then after 3 months MASI scoring 2 was done. There was significant decrease in it from baseline at end of 12 wks, mean 3.4 as shown in table 2.

Table 1: Demographic Variables of Enrolled Patients

\begin{tabular}{|l|l|l|}
\hline Gender & & \\
\hline & Male & $26(37.1 \%)$ \\
\hline & Female & $44(62.9 \%)$ \\
\hline Pattern of melasma & & \\
\hline & Malar & $40(28 \%)$ \\
\hline & Mixed & $32(45.7 \%)$ \\
\hline & Centrofacial & $8(11.4)$ \\
\hline Type of melasma & Mandibular & $2(2.9 \%)$ \\
\hline & & \\
\hline & Epidermal & $50(71.4 \%)$ \\
\hline & Dermal & $11(15.7 \%)$ \\
\hline & Mixed & $9(12.9 \%)$ \\
\hline
\end{tabular}

Table 2: MASI Score

\begin{tabular}{|l|l|l|}
\hline Week & MASI Score & P Value \\
\hline 0 weeks & 18.5 & \\
\hline $12^{\text {th }}$ week & 15.1 & 0.002 \\
\hline
\end{tabular}

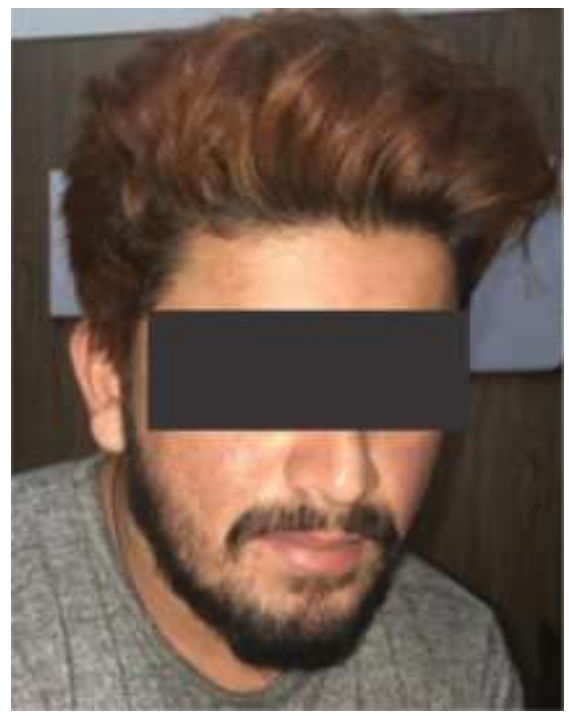

Fig. 1: At start of treatment

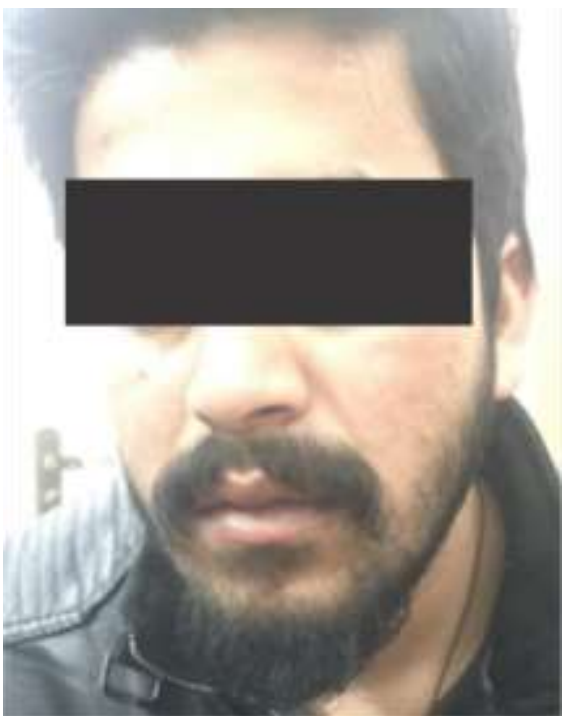

Fig. 2: After 12 weeks of treatment

Figure 3:

\section{Patient Satisfaction}

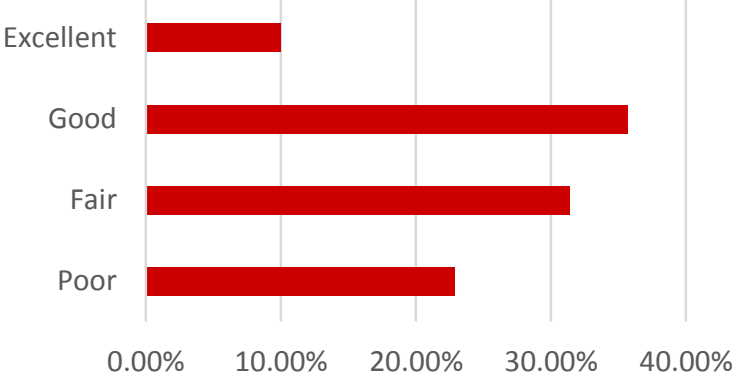

Figure 1 and 2 shows picture of patient at start of treatment and after 12 wks of treatment. No patient suffered from worsening of melasma.

Regarding patient satisfaction good response was in (35.7\%) 25 patients, fair in (31.4\%) 22, poor in (22.9\%) 16 and excellent in (10\%) 7 patients as shown in figure 3 . Further follow up was done for 2 months, it didn't show any reversal of improvement in melasma.

Oral tranexamic acid in low dose was found to be relatively safe for patients. No side effects were noted in 64 $(91.4 \%)$ of patients, abdominal cramps in $3(4.3 \%)$ and oligomenorrhea in 3 (4.3\%) of patients.

\section{DISCUSSION}

Melasma is a common benign acquired skin disorder, consisting of hyperpigmented macules and patches, common on face in symmetrical distribution. ${ }^{1,15}$ Different studies have shown that topical treatments show some efficacy in epidermal type, but not in dermal or mixed type of melasma. ${ }^{5,16,17}$ Various treatment modalities are in use for melasma nowadays. Tranexamic acid is also being used for it.

In this study the patients were given oral tranexamic acid in a dose of $250 \mathrm{mg}$ twice a day for 3 months which is 
like the dose given in study done in Nepal by Karn D et al. 17

Regarding the type of melasma, the commonest type was epidermal which was present in 50 patients $(71.4 \%)$. This is almost like the study done by Nader et al in Iran ${ }^{1}$, epidermal melasma was $63.4 \%$. This difference may be due to less sun exposure on face as most of the population in Iran wears hijab.

In our study, the reduction in MASI score was from $18.5 \pm 1.1$ at start of therapy to $15.1 \pm 1.19$ after 12 weeks which is almost like the reduction in MASI score from 11.08 2.91 to 7.842 .44 recorded in the study done in Nepal by Karn D et al. ${ }^{17}$

The patient satisfaction score according to Likert scale was found to be fair in 22 patients $(31.4 \%)$, good in $25(35.7 \%)$, excellent in $7(10 \%)$ and poor in $16(22.9 \%)$ in our study in charity hospital which is comparable to the score achieved in study done in Nepal by Karn D et al ${ }^{17}$ like it was fair in $40 \%$, good in $32.3 \%$, excellent in $8.50 \%$ and poor in $19.30 \%$ of patients. Such response may be because of our geographical location and skin type.

Our study showed very few side effects with low dose of tranexamic acid like abdominal cramps, oligomenorrhoea in 3 patients each and rest of the patients had no side effects which are almost similar to the study done in Lahore by Safoora et al $^{2}$ and some other studies $18,19,20$. So, the results of our study are somewhat similar to the results attained in other studies.

As oral tranexamic acid in low dose has good result as skin lightening agent and has low side effect profile. So, it can be recommended as a routine treatment of melasma.

The limitations of this study are the small number of participants and shorter duration of study and follow-up should be done for a longer duration to look for recurrences.

\section{CONCLUSION}

It can be concluded from our study that oral tranexamic acid can be used as an alternative treatment of melasma or can be used as an adjuvant to other treatments already being used in its treatment.

\section{REFERENCES}

1. Pazyar N, Yaghoobi R, Zeynalie M, Vala S. Comparison of the efficacy of intradermal injected tranexamic acid vs hydroquinone cream in the treatment of melasma. Clinic, Cosmetic and Investigational Dermatol. 2019; 12:115-122.

2. Amir S, Naseem R. Oral tranexamic acid in treatment of melasma in Pakistani Population: a pilot study. $\mathrm{J}$ of Pakistan Assoc. Dermatol. 2014;24(3):198-203.

3. Tse. TW, Hui E. Tranexamic acid: An important adjuvant in the treatment of melasma. Journal of Cosmetic Dermatol. 2013;12(1):57-66.

4. Goh CL, Lee HC, Thng TGS. Oral tranexamic acid in treatment of melasma: A retrospective analysis, J Am Acad Dermatol. 2016; 75(2):385-392.
5. Lee JH, Park JG, Lim SH, Kim JY, Ahn KY, Kim MY, et al. Localized intradermal microinjection of tranexamic acid for treatment of melasma in Asian patients: A preliminary clinical trial. Dermatol Surg. 2006; 32:626-31.

6. Ebrahimi B, Naeini FF. Topical tranexamic acid as a promising treatment for melasma. J Res Med Sci. 2014;19(8):753-757.

7. Prignano F, Ortonne JP, Buggiani G, Lotti T. Therapeutical approaches in melasma. Dermatol Clin.2007;25:337-42.

8. Cho HH, Choi M, Cho S, Lee JH. Role of oral tranexamic acid in melasma patients treated with IPL and low fluence QS Nd: YAG laser. J Dermatolog Treat. 2013; 24:292-6.

9. $\mathrm{Na} \mathrm{Jl}$, Choi SY, Yang SH, Choi HR, Kang HY, Park KC. Effect of tranexamic acid on melasma: A clinical trial with histological evaluation. J Eur Acad Dermatol Venereol. 2013; 27:1035-9.

10. Kondou S, Okada Y, Tomita Y. Clinical study of effect of tranexamic acid emulsion on melasma and freckles. Skin Res. 2007; 6:309-15.

11. Wu S, Shi H, Wu H, Yan S, Guo J, Sun Y, et al. Treatment of melasma with oral administration of tranexamic acid. Aesthetic Plast Surg. 2012; 36:964-70.

12. Zhang L, Tan WQ, Fang QQ, Zhao WY, Zhao QM et al. Tranexamic Acid for Adults with Melasma: A Systemic Review and Meta-Analysis. BioMed Research International.2018, Article ID 1683414, 13 pages.

13. Bala HR, Lee S, Wong C, Pandaya A, Rodrigues. Oral tranexamic acid for treatment of Melasma. Deramtologic Surgery. 2018;44;(6)814-25.

14. Kim EH, Kim YC, Lee ES, Kang HY. The vascular characteristics of melasma. $\mathrm{J}$ of Dermatological Science. 2007;46(2):111-16.

15. Miot LD, Miot HA, Silva MG, Marques ME. Physiopathology of melasma. An Bras Dermatol. 2009;84(6):623-635.

16. Ejaz A, Raza N, Iftikhar N, Muzzafar F. Comparison of $30 \%$ salicylic acid with jessner's solution for superficial chemical peeling in epidermal melasma. J Coll Physicians Surg Pak. 2008; 18:205-8.

17. Karn D, KC S, Amatya A, Razouria EA, Timalsina M. Oral tranexamic acid for the Treatment of Melasma. Khatmandu Univ Med J. 2012;10(4):40-43.

18. Shin JU, Park J, Oh SH, Lee JH. Oral tranexamic acid enhances the efficacy of low fluence $1064-\mathrm{Nm}$ quality switched neodymium-doped yttrium aluminum garnet laser treatment for melasma in Koreans: A randomized, prospective trial. Dermatolog Surg. 2013;39(3):435-442.

19. Lajevardi V, Ghayoumi R, Abedini et al. Comparison of the therapeutic efficacy and safety of combined oral tranexamic acid and topical hydroquinone $4 \%$ treatment vs. topical hydroquinone $4 \%$ alone in melasma: a parallel-group, assessor- and analyst-blinded, randomized controlled trial with a short term follow up. J of Cosmetic Dermatol. 2017;16(2):235-242.

20. Padhi $T$ and Pradhan S. Oral tranexamic acid with fluocinolone -based triple combination cream versus fluocinolone-based triple combination cream alone in melasma: An open labeled randomized comparative trial. Indian J of Dermatol. 2015;60(5):520. 